Diseases 2014, 2, 296-300; doi:10.3390/diseases2040296

OPEN ACCESS

diseases

ISSN 2079-9721

www.mdpi.com/journal/diseases/

Case Report

\title{
Facial and Ocular Features of Marfan Syndrome
}

\author{
Juan C. Leoni ${ }^{1}$, Juan M. Bowen ${ }^{2}$ and Heidi M. Connolly ${ }^{2, *}$ \\ 1 Department of Cardiology, Mayo Clinic Jacksonville, FL 32224, USA \\ 2 Department of Cardiology, Mayo Clinic Rochester, MN 55905, USA \\ * Author to whom correspondence should be addressed; E-Mail: Connolly.Heidi@mayo.edu; \\ Tel.: +1-507-284-1226; Fax: +1-507-284-1226.
}

External Editor: Maurizio Battino

Received: 13 June 2014; in revised form: 22 September 2014 / Accepted: 10 October 2014 /

Published: 17 October 2014

\begin{abstract}
Marfan syndrome is the most common inherited disorder of connective tissue affecting multiple organ systems. Identification of the facial, ocular and skeletal features should prompt referral for aortic imaging since sudden death by aortic dissection and rupture remains a major cause of death in patients with unrecognized Marfan syndrome. Echocardiography is recommended as the initial imaging test, and once a dilated aortic root is identified magnetic resonance or computed tomography should be done to assess the entire aorta. Prophylactic aortic root replacement is safe and has been demonstrated to improve life expectancy in patients with Marfan syndrome. Medical therapy for Marfan syndrome includes the use of beta blockers in older children and adults with an enlarged aorta. Addition of angiotensin receptor antagonists has been shown to slow the progression of aortic root dilation compared to beta blockers alone. Lifelong and regular follow up in a center for specialized care is important for patients with Marfan syndrome. We present a case of a patient with clinical features of Marfan syndrome and discuss possible therapeutic interventions for her dilated aorta.
\end{abstract}

Keywords: Marfan syndrome; thoracic aortic aneurysm; aortic valve sparing root replacement 


\section{Introduction}

A 59-year-old woman presents to your office with characteristic facial and ocular features of Marfan syndrome (MFS) including dolichocephaly (elongated face), down-slanting palpebral fissures, high and arched palate, dental crowding and iridodonesis (vibration of the iris with eye movement due to lens dislocation). See video (in supplementary file). She was diagnosed with Marfan at age 3. She has no prior sternotomies. Her family history is notable for father suspected of having MFS and dying suddenly in his mid 50's while sitting at home (no autopsy performed). Although she has 3 unaffected siblings, her 2 children have the syndrome with son requiring aortic valve-sparing surgery at a young age due to progressive aortic dilation. Additional diagnostic features of MFS include aortic dilatation and bilateral ectopia lentis with multiple prior interventions. She had prior wrist and thumb signs that have disappeared with age-related reduced joint mobility and weight gain, as well as known dural ectasia on MRI. She had never been tested for fibrillin-1 gene mutation due to having typical phenotypical characteristics of Marfan. She met diagnostic criteria for MFS based on the revised Ghent nosology (positive family history, systemic score $>7$, ectopia lentis and aortic criteria Z-score $>2$ ) [1]. She has followed regularly with imaging of her dilated proximal aorta. One year ago the $2 \mathrm{D}$ echocardiogram demonstrated an aortic sinus dimension of $42 \mathrm{~mm}$, with no significant valvular heart disease. Today, the proximal aorta measures $45 \mathrm{~mm}$ with normal left ventricular function and no aortic valvulopathy. An MRA is also performed demonstrating an aortic sinus diameter of $48 \mathrm{~mm}$. Her Z-score measured for her aortic sinuses is 4.79 (height $195.5 \mathrm{~cm}$, weight $112.6 \mathrm{~kg}$, BSA $2.45 \mathrm{~m}^{2}$ ). Her medical management includes losartan $50 \mathrm{mg}$ PO BID. She was not on beta blocker therapy due to prior drug intolerance.

\section{What Would You Do Next?}

a. Do nothing. Continue annual imaging evaluation until the aortic root diameter is $>50 \mathrm{~mm}$.

b. Refer to surgery for aortic valve-sparing root replacement.

c. Refer to surgery for a composite graft replacement (Bentall procedure).

d. Add a dihydropyridine calcium channel blocker to decrease the progression of aortic dilation.

\section{Diagnosis}

Dilated aortic root in a patient with Marfan syndrome.

\section{What To Do Next}

Serial aortic imaging studies in this patient demonstrated progressive aortic root dilatation close to 50 $\mathrm{mm}$ without associated aortic valve regurgitation. Based on a family history of presumed aortic dissection in her father and need for early surgery in her son, rapid progression of her aortic root size in one year, and patient preference for earlier intervention it was recommended to proceed with surgery. She underwent elective aortic valve-sparing root replacement with hemiarch repair using a Dacron graft and reimplantation of the coronary arteries into the prosthesis. Her initial postoperative course was complicated with left vocal cord paresis which has now been resolved. 


\section{Comment}

Marfan syndrome (MFS) is the most common inherited disorder of connective tissue affecting multiple organ systems [2]. It is an autosomal dominant condition due to a mutation in the fibrillin-1 gene (FBN1) leading to deficiency or malformation of the fibrillin-1 protein, a glycoprotein in the extracellular matrix, as well as excessive transforming growth factor $\beta$ (TGF- $\beta$ ) signaling, resulting in fragmentation and disarray of elastic fibers $[3,4]$, as well as activation of the mitogen-activated protein kinase (MAPK)/extracellular signal-regulated kinase (ERK) cascade implicated in aneurysm progression [5]. It has an incidence of 2-3 per 10,000 individuals without predilection for gender, race or ethnicity. Early identification and appropriate management are critical since these patients are prone to life-threatening cardiovascular complications. Identification of the facial, ocular and skeletal features should prompt referral for aortic imaging since sudden death by aortic dissection and rupture remains a major cause of death in patients with unrecognized Marfan syndrome. Mean survival of untreated patients is 40 years, and asymptomatic aortic dilatation is present in $60 \%-80 \%$ of affected individuals with a variable rate of progression.

Prophylactic aortic root replacement with a composite graft is safe and has been demonstrated to improve life expectancy in patients with Marfan syndrome [6]. Aortic valve-sparing aortic root surgery has also been deemed safe in those patients with anatomically normal valves. Our patient's left ventricular function was normal, but left ventricular dysfunction can occur independently of aortic root or valvular disease. Echocardiography is recommended as the initial imaging test. Once a dilated aortic root is identified, MRA or CTA should be done to assess the entire aorta. Most patients will have aneurysmal change limited to the proximal aorta and can be followed with periodic echocardiography. Patients should undergo surgery when the aortic root maximal diameter is $>50 \mathrm{~mm}$, but earlier repair should be done when there are indicators of increased risk, including a family history of dissection, progressive dilatation of $>5 \mathrm{~mm} /$ year, severe aortic or mitral regurgitation, or desire for pregnancy. Medical therapy for MFS includes the use of beta blockers (BB) in children and adults regardless of the presence or absence of an enlarged aorta [7]. Addition of angiotensin receptor antagonists (ARB) to BB has been shown to slow the progression of aortic root dilation compared to BB alone [8]. The use of losartan has been shown to reduce the rate of aortic growth rates before and after surgical replacement and thus it should be continued on this patient [9-11]. Calcium channel blockers (CCB) have only been evaluated in small trials and are sometimes prescribed if a BB is contraindicated based on their blood pressure lowering effect properties. However, they are less useful due to the relative lack of effect on cardiac inotropic state [12]. More recent animal studies using amlodipine or placebo in MFS vs. wild-type mice showed increased ascending aortic size, aortic growth and early mortality in the CCB group, suggesting potential deleterious effects on MFS individuals [10]. There is promising research for other pharmacologic therapies in the pathogenesis of thoracic aortic aneurysm; these include an ongoing trial with children and young adults comparing atenolol versus losartan on the rate of aortic root growth over three years [13].

Lifelong and regular follow up in a center for specialized care is important for patients with MFS. Even after repair, Marfan patients remain at risk for dissection. Stable patients should have a yearly visit with associated aortic imaging. 


\section{Supplementary Materials}

Supplementary materials can be accessed at: http://www.mdpi.com/2079-9721/2/3/296/s1.

\section{Acknowledgments}

We thank B.A. for participating in the development of this manuscript.

\section{Conflicts of Interest}

The authors declare no conflict of interest.

\section{References}

1. Loeys, B.L.; Dietz, H.C.; Braverman, A.C.; Callewaert, B.L.; de Backer, J.; Devereux, R.B.; Hilhorst-Hofstee, Y.; Jondeau, G.; Faivre, L.; Millewicz, D.M.; et al. The revised Ghent nosology for the Marfan syndrome. J. Med. Genet. 2010; 47, 476-485.

2. Ammash, N.; Sundt, T.; Connolly, H. Marfan Syndrome-Diagnosis and management. Curr. Probl. Cardiol. 2008, 33, 7-39.

3. Dietz, H.; Cutting, G.; Pyeritz, R.E.; Maslen, C.L.; Sakai, L.Y.; Corson, G.M.; Puffenberger, E.G.; Hamosh, A.; Nanthakumar, E.J.; Curristin, S.M.; et al. Marfan Syndrome caused by a recurrent de novo missense mutation in the fibrillin gene. Nature 1991, 352, 337-339.

4. Habashi, J.P.; Judge, D.P.; Holm, T.M.; Cohn, R.D.; Loeys, B.L.; Cooper, T.K.; Myers, L.; Klein, E.C.; Liu, G.; Calvi, C.; et al. Losartan, an $\mathrm{AT}_{1}$ antagonist, prevents aortic aneurysm in a mouse model of Marfan syndrome. Science 2006, 312, 117-121.

5. Attenhofer Jost, C.H.; Greutmann, M.; Connolly, H.M.; Weber, R.; Rohrbach, M.; Oxenius, A.; Kretschmar, O.; Luscher, T.F. Matyas, G. Medical Treatment of Aortic Aneurysm in Marfan Syndrome and other Heritable Conditions. Curr. Cardiol. Rev. 2014, 10, 161-171.

6. Hiratzka, L.F.; Bakris, G.L.; Beckman, J.A.; Bersin, R.M.; Carr, V.F.; Casey, D.E., Jr; Eagle, K.A.; Hermann, L.K.; Isselbacher, E.M.; Kazerooni, E.A.; et al. ACCF/AHA/AATS/ACR/ASA/SCA/ $\mathrm{SCAI} / \mathrm{SIR} / \mathrm{STS} / \mathrm{SVM}$ Guidelines for the diagnosis and management of patients with thoracic aortic disease. J. Am. Coll. Cardiol. 2010, 55, e27-e129.

7. Shores, J.; Berger, K.R.; Murphy, E.A.; Pyeritz, R.E. Progression of aortic dilation and the benefit of long-term beta-adrenergic blockage in Marfan's syndrome. N. Engl. J. Med. 1994, 330, 1335-1341.

8. Chiu, H.H.; Wu, M.H.; Wang, J.K.; Lu, C.W.; Chiu, S.N.; Chen, C.A.; Lin, M.T.; Hu, F.C. Losartan added to $\beta$-blockade therapy for aortic root dilation in Marfan syndrome: a randomized, open-label pilot study. Mayo Clin. Proc. 2013, 88, 271-276.

9. Brooke, B.S.; Habashi, J.P.; Judge, D.P.; Patel, N.; Loeys, B.; Dietz, H.C., III. Angiotensin II blockade and aortic-root dilation in Marfan's syndrome. N. Engl. J. Med. 2008, 358, 2787-2795.

10. Williams, A.; Davies, S.; Stuart, A.G.; Wilson, D.G.; Fraser, A.G. Medical treatment of Marfan syndrome: A time for change. Heart 2008, 94, 414-421. 
11. Groenink, M.;den Hartog, A.W.; Franken, R.; Radonic, T.; de Waard, V.; Timmermans, J.; Scholte, A.J.; van der Berg, M.P.; Spijkerboer, A.M.; Marquering, H.A.; et al. Losartan reduces aortic dilatation rate in adults with Marfan syndrome: A randomized controlled trial. Eur. Heart J. 2013, 34, 3491-3500.

12. Doyle, J.; Habashi, J.; Lindsay, M.; Bedja, D.; Dietz, H.C. Calcium channel blockers exacerbate aortic disease and cause premature lethality in Marfan syndrome. Circulation 2010, 122, A14647.

13. Lacro, R.V.; Dietz, H.C.; Wruck, L.M.; Bradley, T.J.; Colan, S.D.; Devereux, R.B.; Klein, G.L.; Li, J.S.; Minich, L.L.; Paridon, S.M. et al. Rationale and design of a randomized clinical trial of beta-blocker therapy (atenolol) versus angiotensin II receptor blocker therapy (losartan) in individuals with Marfan syndrome. Am. Heart J. 2007, 154, 624-631.

(C) 2014 by the authors; licensee MDPI, Basel, Switzerland. This article is an open access article distributed under the terms and conditions of the Creative Commons Attribution license (http://creativecommons.org/licenses/by/4.0/). 